\title{
Reportando Problemas Ambientais: Desenvolvimento de Vídeos Utilizando Stop Motion
}

\author{
Emily Silva Gomes dos Santos ${ }^{1}$, Andréa Pereira Mendonça ${ }^{1}$, Laís Cássia Monteiro \\ de Souza Barreto ${ }^{1}$
}

${ }^{1}$ Mestrado Profissional em Ensino Tecnológico (MPET) - Instituto Federal do Amazonas (IFAM) - Manaus, AM - Brasil

\{emilysgs31, andreapmendonca, lais.cms.barreto\} @gmail.com

\begin{abstract}
Many students have the belief that the consequences of environmental problems will not directly affect them and developing a critical reflection on these issues is still a challenge. To overcome this challenge, we developed a teaching strategy where students used the Stop Motion animation technique to produce videos depicting local environmental problems from the observation of Nascentes do Mindu Municipal Park in Manaus, Amazonas. As a result, two videos were produced that deal with the problems observed. This experience brought perspectives to different works that included the creation of a video shoot on environmental problems portrayed by the students themselves.
\end{abstract}

Resumo. Muitos alunos possuem a crença de que as consequências dos problemas ambientais não os afetarão diretamente e desenvolver uma reflexão crítica sobre estes assuntos ainda é um desafio. Para superar esse desafio, desenvolvemos uma estratégia de ensino onde os alunos utilizaram a técnica de animação Stop Motion para produzir vídeos retratando os problemas ambientais locais a partir da observação do Parque Municipal Nascentes do Mindu, em Manaus-Amazonas. Como resultado, foram produzidos dois vídeos que tratam sobre os problemas observados. Esta experiência trouxe perspectivas para diferentes trabalhos que incluem a criação de um acerto de vídeos sobre problemas ambientais retratados pelos próprios estudantes.

\section{Introdução}

No ensino fundamental, terceiro e quarto ciclos, o estudo de questões ligadas ao Meio Ambiente é promovido na disciplina de Ciências Naturais, de forma transversal, nos eixos temáticos Vida e Ambiente, Tecnologia e Sociedade, Terra e Universo, Ser Humano e Saúde (BRASIL, 1998).

Embora muitas questões de alcance mundial e de frequente repercussão na mídia possam ser tratadas dentro da temática Meio Ambiente, como por exemplo, alteração global do clima, perda da diversidade genética e desmatamento, é comum observarmos nos estudantes certo desinteresse por estas questões, algumas vezes, arraigados na expectativa de que os problemas noticiados não atingirão sua geração, nem tratarão impactos imediatos a localidade onde moram.

Isto, por sua vez, repercute diretamente no processo de ensino e aprendizagem, na medida em que os estudantes acabam por não se engajarem na reflexão crítica sobre estas questões e por não desenvolverem uma nova ética capaz de conciliar sociedade e natureza (BRASIL, 2001). 
Porém, acreditamos que é possível potencializar o engajamento dos estudantes com a adoção de estratégias que os aproximem da observação do ambiente onde vivem, das questões que afetam sua comunidade, ou que transformaram a localidade onde moram. Isto é, partir da realidade concreta dos estudantes para então sensibilizá-los para os impactos coletivos e também para os problemas de dimensões globais.

Neste trabalho, nós relatamos os resultados obtidos com estudantes de $7^{\circ}$ e $8^{\circ}$ ano do ensino fundamental de uma Escola Municipal de Manaus no Amazonas no estudo da temática Meio Ambiente. O objetivo do trabalho era que os estudantes pudessem representar problemas ambientais causados pela ação humana com impactos na localidade geográfica próxima a escola. Isto é, estudar a temática Meio Ambiente a partir da realidade concreta desses estudantes.

Para auxiliá-los nesse processo de representação, foi viabilizada uma visita ao Parque Municipal Nascentes do Mindu (PMNM), uma unidade de conservação situada próximo a escola. Nesta visita, os estudantes puderam conhecer os recursos naturais conservados, como também descobrir o histórico de impactos ambientais, muitas vezes causados pela própria comunidade local pelo uso inconsciente dos recursos do Parque.

As representações dos problemas ambientais identificados no Parque Municipal Nascente do Mindu (PMNM) foram materializadas pelos estudantes em vídeos, produzidos com a técnica de animação Stop Motion, compreendida como a disposição sequencial de fotografias diferentes de um mesmo objeto para simular movimento. Esta perspectiva de trabalhar com captura de fotos e produção de vídeos promoveu engajamento dos estudantes na atividade, uma vez que o vídeo é considerado por eles um elemento comunicativo que desperta interesse. Os detalhes sobre o Parque visitado pelos estudantes, a técnica Stop Motion, o percurso metodológico, assim como os resultados obtidos são apresentados nas próximas seções.

\section{Parque Municipal Nascentes do Mindu (PMNM)}

O Parque Municipal Nascentes do Mindu foi criado em 2006 com o objetivo de proteger as nascentes que formam o igarapé do Mindu - uma bacia urbanizada de aproximadamente 20 quilômetros de extensão, cujo estado natural foi afetado pela degradação causada pelo homem. Alguns trechos desse igarapé encontram-se assoreados, aterrados, sendo suas margens ocupadas e sem infraestrutura, com presença de lixo em quase todo seu percurso, a exceção de suas nascentes (CASSIANO; COSTA, 2012).

Este Parque (vide Figura 1) possui área de 16 hectares, está localizado na Zona Leste de Manaus, no Bairro Cidade de Deus, conta com uma flora de $70 \%$ de espécies nativas e fauna composta por pequenos roedores e mamíferos, como sauins-de-coleira, macacos-de-cheiro e também aves, como tucanos, saracuras, corujas, gaviões, fauna silvestre em vida livre (BRASIL, 2016). Por ser uma área com características naturais relevantes, passíveis de proteção, este Parque é caracterizado com uma Unidade de Conservação de Proteção Integral, segundo a Lei 9.985 de 18 de julho de 2000 que abriga e conserva parte da biodiversidade de Manaus.

Os parques em áreas urbanas geralmente são locais ricos em biodiversidade, agregando em sua maioria a fauna e a flora da localidade e se constituem em ambientes que podem ser utilizados não somente para o lazer como para várias outras atividades que contemplem o uso da natureza como a educação ambiental (DRAY; SIMONETTI, 2012). 
Estes espaços, dentro de suas finalidades, promovem oportunidades para realização de pesquisa científica, ações de educação ambiental, turismo ecológico sustentável e outras formas de geração de renda com menos impacto ambiental, podendo, dessa forma, estimular a economia verde e promover diretamente a qualidade de vida das populações locais (VALENTI, 2012).

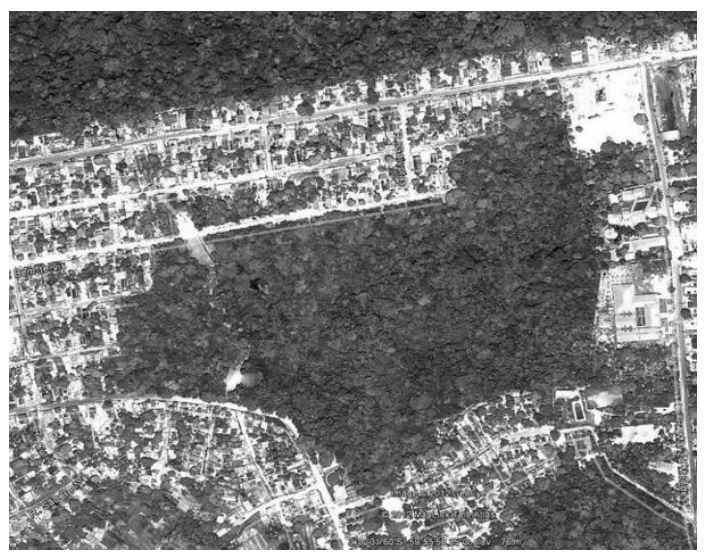

Figura 1. Imagem via satélite do Parque. Fonte: (BRASIL, 2016).

Abordar questões ambientais em ambientes educacionais, contribui para o crescimento de uma sociedade mais crítica e ciente da relevância de se preservar os recursos naturais (OLIVEIRA, et al., 2016). Acredita-se que a utilização dos recursos naturais como água, flora, fauna e solo proporcionam alternativas para sensibilizar a sociedade quanto aos problemas socioambientais ocorrentes no planeta nas últimas décadas, valorizando a conservação do meio ambiente.

As nascentes do Parque estão localizadas em pontos específicos, duas delas nascem próximas uma da outra e a terceira é distante, tendo um acesso mais isolado, pois a vegetação ainda está intacta neste ponto. Os moradores das comunidades e bairros próximos ao parque são convidados a participarem dos eventos no local, os quais ocorrem em datas comemorativas, como por exemplo no dia da água. Porém, o parque ainda é alvo da ação predatória do homem, que conscientemente ou não, utiliza os recursos da unidade para diferentes fins como balneabilidade nos lagos naturais formados pelas nascentes e retiradas de frutos das árvores. Além disso, frequentemente são detectadas a queima de resíduos em casas próximas ao Parque, sem a preocupação de conter o fogo para que ele não se espalhe para a vegetação do Parque, o que pode comprometer potencialmente os recursos naturais encontrados na unidade, assim como a existência das nascentes abrigadas ali.

A distância do Parque para a escola Municipal Raul de Queiroz de Menezes Veiga, escola cujo alunos participaram deste trabalho, é de aproximadamente 650 metros. Portanto, o Parque é parte integrante da localidade onde moram os estudantes, e foi escolhido como uma estratégia para despertá-los para a responsabilidade social com o meio ambiente, tomando como ponto de partida sua própria realidade local.

Cabe destacar ainda, que este Parque é estratégico para o estudo da disciplina de Ciências, principalmente para as escolas localizadas em suas proximidades, pois o Parque fornece vários recursos naturais para tratar temas como solo, vegetação, fauna, recursos hídricos, poluição e problemas ambientais. No caso deste trabalho, enfatizamos o tema problemas ambientais, sendo o mesmo retratado por meio da técnica de animação Stop Motion, descrita a seguir. 
VI Congresso Brasileiro de Informática na Educação (CBIE 2017)

Anais do XXIII Workshop de Informática na Escola (WIE 2017)

\section{Stop Motion e sua Aplicação no Ensino}

Stop Motion pode ser definida como uma técnica que produz uma ilusão de movimento, a partir da captura de imagens paradas, de objetos vivos ou inanimados, que vão sendo mudados de posição quadro a quadro e, posteriormente, montados em sequência na forma de vídeo, que pode incluir efeitos sonoros, músicas e textos (FARACHE, 2011).

Embora essa técnica seja conhecida em virtudes das produções cinematográficas (por exemplo, os filmes A Noiva Cadáver e a Fuga das Galinhas), é possível utilizá-la para propósito geral, utilizando-se de materiais de baixo custo, tais como, massa de modelar, papéis, cenários em cartolina, entre outros.

Para construir uma animação utilizando esta técnica, é necessário seguir um conjunto de etapas que iniciam com a criação de um roteiro, na qual a história que se deseja contar é organizada de forma lógica. Posterior a definição do roteiro, parte-se para a confecção do cenário e dos personagens. Após isso, são feitas as fotografias, que devem capturar uma sequência de imagens dos personagens, com pequenas mudanças de posição dentro do cenário. Finalizada esta etapa, um vídeo é construído a partir da edição das fotos em computador, utilizando-se software específico para isto, tal como, o Windows Movie Maker, utilizado neste trabalho. Neste processo de edição, é possível enriquecer o vídeo com a adição de textos, músicas e outros efeitos sonoros.

O trabalho com Stop Motion no contexto de sala de aula incentiva a autoria, criatividade, o trabalho cooperativo e a familiarização com os recursos tecnológicos, além de promover a aprendizagem de conteúdos didáticos. De Freitas et al (2016), por exemplo, desenvolveram um trabalho com técnicas de Stop Motion na produção de curta metragem para trabalhar o conteúdo de Expressionismo Abstrato com alunos do Ensino Médio em uma escola pública.

Lima e Camillo (2005), por sua vez, utilizaram Stop Motion para tratar conteúdos de Química com alunos de ensino médio, assim como Lima et al (2015) que utilizaram as animações Stop Motion para ajudar os alunos participantes do Exame Nacional do Ensino Médio - ENEM a compreenderem o sistema digestivo. De Melo, Da Silva e Leão (1986), por sua vez, utilizaram Stop Motion para estudar a Lei de Boyle, tratando questões envolvidas no Estudo dos Gases, utilizando-se da construção histórica do experimento realizado por Robert Boyle como tema central do vídeo.

Neste trabalho utilizamos a técnica Stop Motion para que alunos do ensino fundamental retratassem os problemas ambientais verificados por eles durante uma visita realizada na unidade de conservação Parque Municipal Nascente do Mindu, localizada nas proximidades da escola. O objetivo era o de permitir que estes estudantes fizessem uma reflexão sobre a temática Meio Ambiente a partir da realidade concreta deles.

\section{Procedimentos Metodológicos}

O trabalho foi realizado na forma de uma oficina sobre Stop Motion oferecida para alunos do ensino fundamental ( $7^{\mathrm{a}}$ e $8^{\mathrm{a}}$ série) da Escola Municipal Raul de Queiroz de Menezes Veiga, situada em Manaus-AM. A escola ofereceu esta atividade como oficina com a intenção de abrir espaço para atividades complementares dentro da escola, com adesão voluntária e que permitisse aos estudantes ampliar seus repertórios de conhecimentos acadêmicos e tecnológicos.

A oficina teve carga horária de 18 (dezoito) horas, organizadas em 5 (cinco) dias, no contra turno dos alunos que tinham aula no período da manhã e participavam da oficina 
VI Congresso Brasileiro de Informática na Educação (CBIE 2017)

Anais do XXIII Workshop de Informática na Escola (WIE 2017)

à tarde, nas dependências da escola. Inscreveram-se na oficina 9 (nove) alunos, os quais realizaram as seguintes atividades:

- Prática assistida que aconteceu no primeiro dia de atividade, com duração de 03 (três) horas, na qual os estudantes conheceram o conceito de Stop Motion, assistiram pequenos animações em vídeos e produziram uma animação a partir de um conjunto de fotos disponibilizadas na internet. O objetivo era que os alunos conhecessem a técnica de animação e se familiarizassem com a edição de vídeo, utilizando o Windows Movie Maker. Ao final desta atividade, os alunos foram divididos em dois grupos, com a seguinte missão: cada grupo deveria produzir um vídeo que tratasse sobre problemas ambientais locais.

- Visita guiada ao Parque Municipal Nascentes do Mindu (PMNM) realizada no segundo dia da oficina, com duração de 01 (uma) hora, conforme ilustrada na Figura 2. O objetivo desta atividade era proporcionar aos alunos conhecimentos sobre os recursos naturais protegidos no Parque e dos impactos ambientais causados pela própria população. No local, os alunos foram orientados nas trilhas que davam acesso às nascentes por um guia do Parque e a partir da visita cada grupo pôde adquirir subsídios para a construção de seus respectivos vídeos.

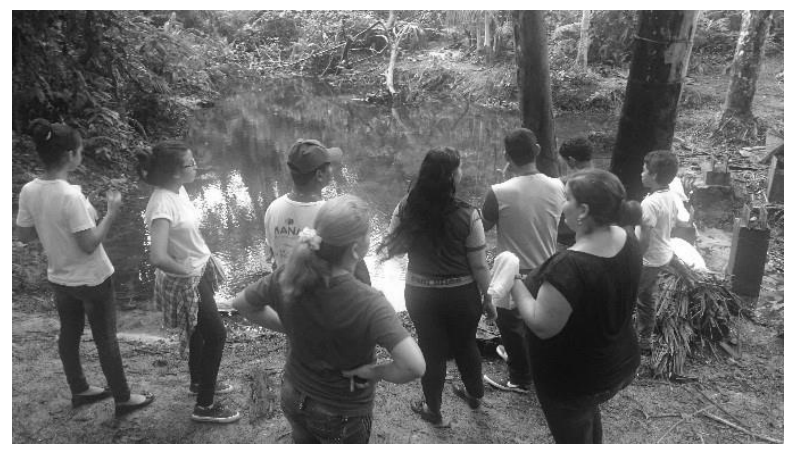

Figura 2. Visita no Parque. Fonte: Acervo de fotos dos autores.

- Elaboração do roteiro do vídeo, com duração de aproximadamente 1 (uma) hora e realizada no mesmo dia após a visita guiada ao Parque. Os grupos, baseados nas anotações feitas durante a visita guiada ao Parque, construíram o roteiro da história a ser contada em vídeo, definindo também as cenas, personagens, textos que deveriam ser integradas ao vídeo e a trilha sonora.

- Confecção de cenários, personagens e tomadas de fotos (Figuras 3 e 4, parte superior). Esta atividade teve duração de 8 (oito) horas, sendo realizada em três dias de trabalho. Para a confecção de cenários e personagens os estudantes utilizaram materiais de baixo custo, conforme descrito no Quadro 1. As fotos foram realizadas com utilização de 01 (uma) câmera fotográfica e 01 (um) smartphone.

Quadro 1. Materiais e recursos utilizados para a confecção dos cenários e personagens. Fonte: Próprios autores.

Materiais de Baixo Custo
03 Tesouras, 04 Folhas de papel crepom, 02 Folhas de Isopor, 02 Caixas de massa de modelar, 01 pacote de papel colorido, 01 Caixa de lápis de cor, 10 folhas de papel ofício, 05 Bastões de cola, 01 Pistola para cola quente, 01 Tubo de cola branca, 01 Tubo de cola 
VI Congresso Brasileiro de Informática na Educação (CBIE 2017)

Anais do XXIII Workshop de Informática na Escola (WIE 2017)

\begin{tabular}{|l|l|}
\hline & $\begin{array}{l}\text { de Isopor, 02 Caixas de papelão, 02 Pincéis, 02 Caixas de tinta } \\
\text { guache. }\end{array}$ \\
\hline
\end{tabular}

- Edição dos vídeos e compartilhamento no Youtube. Atividades realizadas com duração de 4 (quatro) horas, na qual os grupos utilizaram o computador e o Windows Move Maker para editar os vídeos, incluir trilha sonora e textos.

- Socialização do projeto, com duração de 1 (uma) hora. Esta atividade teve por objetivo apresentar as animações em vídeos produzidas pelos grupos, compartilhando com a comunidade escolar suas percepções sobre os problemas ambientais diretamente associados a comunidade onde vivem.

\section{Resultados e Discussões}

Como resultado da oficina, os grupos de estudantes produziram dois vídeos retratando as suas percepções sobre as questões ambientais percebidas a partir da visita guiada ao Parque. Um vídeo tratava sobre o tema "poluição das nascentes" e o outro sobre "as atitudes do homem com relação a natureza".

\subsection{Vídeo com o Tema: Poluição das nascentes}

O tema "Poluição das Nascentes" foi retratado em um vídeo (Figura 3, parte inferior) que mostra a degradação da nascente do rio após visita de pessoas da comunidade.

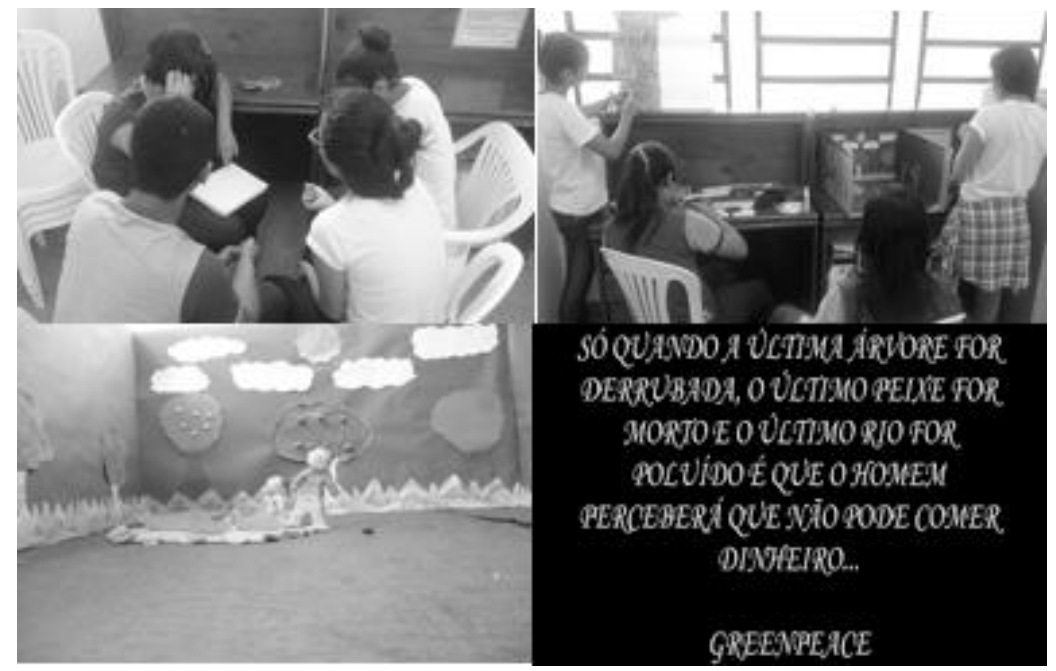

Figura 3. Ambiente antes de ser frequentado pelo homem. Fonte: Próprios autores.

O cenário inicial do vídeo mostra o ambiente do Parque, com seu lago, as árvores com frutos, o céu ensolarado e a vida existente no local antes de ser frequentado pela comunidade. Após isso, surgem duas pessoas, moradores dos arredores, que visitam o Parque com a intenção de tomar banho no lago, e estas pessoas levam comida e bebida para passar uma tarde, como se fosse um balneário. O vídeo mostra, que após um tempo as pessoas vão embora e esquecem de recolher o lixo produzido a partir de sua alimentação. Após a saída dos visitantes, começa a chover e o lixo se acumula nas águas, matando os peixes do lago e tornando aquele ambiente poluído. A fim de causar impacto em quem está assistindo o vídeo, levando-o a refletir sobre o tema, o vídeo é finalizado com a frase do Greenpeace: "Só quando a última árvore for derrubada, o último peixe for morto e o último rio for poluído é que o homem perceberá que não pode comer dinheiro". 
VI Congresso Brasileiro de Informática na Educação (CBIE 2017)

Anais do XXIII Workshop de Informática na Escola (WIE 2017)

Este vídeo foi intitulado "Poluindo o Ambiente", tem duração de 1 minuto e 17 segundos e foi produzido com uma sequência de 98 fotos, estando o vídeo disponível para acesso em https://goo.gl/MF0YzB.

\subsection{Vídeo com o Tema: As atitudes do homem com relação a natureza}

Este vídeo também teve como cenário o próprio Parque (Figura 4, parte inferior) e mostra um conjunto de atitudes da comunidade que causam degradação no meio ambiente tem impactos diretos sobre a própria comunidade.

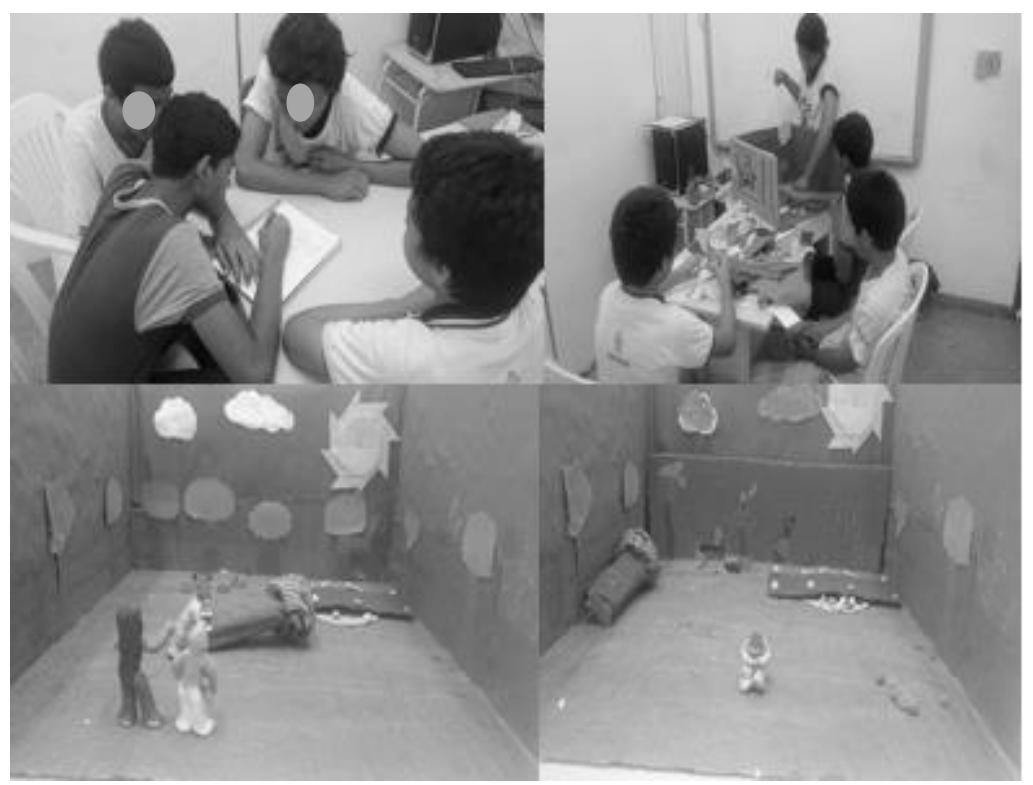

Figura 4: Ambiente do Parque. Fonte: Próprios autores.

O cenário inicial do vídeo mostra o Parque com suas árvores cheias de frutos e a ponte que passa pelos pequenos caminhos que as águas das nascentes fazem. Esse ambiente é então alterado por um grupo de homens que, ao frequentarem o local, avistam uma árvore com frutos e desejam comê-los. Um dos homens, o mais inconsciente, ao perceber que não conseguirá pegar os frutos, resolve derrubar a árvore. Além disso, o homem, acompanhado de seus amigos, joga lixo enquanto passeia pela ponte que passa pela água das nascentes. Depois, avista uma grande aranha caranguejeira e ateia fogo contra ela na intenção de matá-la. O fogo toma maiores proporções e acaba queimando uma parte da vegetação. Seus amigos resolvem tirá-lo do local, mas ele corre e acaba se perdendo na mata. Ao amanhecer, depois de uma noite na mata, o homem está com fome, mas não tem frutos, pois ele derrubou a árvore que tinha frutos. Ele vai em busca de água para beber, mas a água está poluída com o lixo que ele jogou, e então ele percebe que fez algo errado, surge então a frase: "O que foi que eu fiz?".

Este vídeo foi intitulado "As Atitudes erradas do homem", tem duração de 2 minutos e 14 segundos, e foi produzido com uma sequência de 127 fotos, estando o vídeo disponível para acesso em https://goo.gl/b5AXGZ.

\subsection{Algumas Questões Pedagógicas}

A adoção do Stop Motion nos permitiu observar que esta técnica promove o engajamento dos estudantes na assimilação do conteúdo, desperta a criatividade e motiva o trabalho cooperativo. Para compor o vídeo, os estudantes compartilharam suas opiniões e se 
organizaram na divisão das atividades: os que dominavam melhor o computador, trabalharam na manipulação do software de edição de vídeo; os que possuíam melhores habilidades artísticas, construíram o cenário e os personagens; os que manipulavam melhor a câmera fotográfica ou um smartphone tiravam as fotos; os que eram mais articulados com as palavras escreviam o roteiro. Isto é, os estudantes trabalharam cooperativamente, respeitando as habilidades individuais para que a atividade estivesse finalizada dentro do tempo estabelecido. Para Oliveira, et al. (2014), essa técnica se mostra eficaz pois se observa nos discentes total envolvimento e participação na atividade em todas as etapas.

A técnica pode ser utilizada em diferentes disciplinas e fazer uso dos recursos que a escola dispõe, não estando restrito aos materiais utilizados e descritos neste trabalho. Os recursos essenciais são uma máquina fotográfica ou um telefone com câmera, um computador com um programa que edite as fotos, a vontade da escola e dos professores em utilizar esta técnica, e a criatividade dos alunos.

No caso deste trabalho, os vídeos produzidos foram compartilhados no YouTube permitindo que a escola divulgue o trabalho dos estudantes, e também componha, pouco a pouco, um portfólio digital sobre a temática "Problemas Ambientais".

Tratando-se especificamente sobre o estudo da temática em questão, o desenvolvimento de um comportamento consciente sobre os problemas ambientais e do senso de responsabilidade individual para com o meio ambiente requer tempo e o desenvolvimento de ações contínuas envolvendo a escola, a família e a comunidade local. Contudo, o propósito do trabalho foi alcançado na medida em que possibilitou aos estudantes representar os problemas ambientais de impacto em sua própria localidade, sensibilizando-os para a preservação do meio ambiente.

Além disso, o processo de visitação do Parque e de construção dos vídeos promoveu nos estudantes um sentimento de "aprendizagem aplicada", pois até então o estudo dos Temas Transversais, tal como Meio Ambiente, se dava sob uma perspectiva mais teórica.

O desenvolvimento de atividades complementares no formato de oficina foi observado pelos alunos como uma atividade que os permitem ter liberdade de escolha e aprendizagem além dos conteúdos estabelecidos para a sua série escolar. Quanto a adoção do Stop Motion, os alunos consideraram que a técnica, embora trabalhosa, promove a criatividade e pode ser posta em prática com poucos recursos, favorecendo até mesmo as escolas que não dispõe de uma boa infraestrutura de laboratório.

\section{Considerações Finais}

Neste artigo apresentamos os resultados de um trabalho realizado com alunos do ensino fundamental sobre o estudo da temática "Meio Ambiente", no qual foi utilizado a técnica Stop Motion para representar problemas ambientais causados pela ação humana com impactos na localidade geográfica em que vivem os estudantes. A sensibilização para o trabalho ocorreu por meio de uma visita ao Parque Municipal Nascentes do Mindu (PMNM), em Manaus/AM - uma unidade de conservação situada próximo a escola - e que é alvo de ações de degradação causadas pelos próprios habitantes da localidade. 
Como resultado do trabalho, foram produzidos com a técnica de animação Stop Motion dois vídeos que estão acessíveis no YouTube: um, retratando a poluição das nascentes do rio, e outro retratando ações humanas que degradam a natureza.

Com estes vídeos a escola inicia um portfólio digital de vídeos sobre a temática Meio Ambiente. A ideia é aumentar esse acervo sobre a temática com trabalhos que integrem outros estudantes e professores, numa ação multidisciplinar envolvendo Ciências, Artes e Informática. Os vídeos também podem ser utilizados como uma atividade de impacto social, para sensibilização da comunidade local, chamando atenção dos moradores e visitantes do Parque Municipal Nascentes do Mindu (PMNM) para a necessidade da preservação ambiental.

Por fim, cabe destacar que a intenção deste trabalho, não era intelectualizar questões ambientais complexas, mas sim, fazer os alunos vivenciarem de forma participativa a própria realidade, podendo ressignificar objetos, recursos e situações que fazem parte de seu dia-a-dia, e que acabam perdendo importância ou viram problemas corriqueiros, como no caso deste projeto, onde alguns dos moradores frequentam o Parque sem qualquer sensibilidade de preservação.

\section{Agradecimentos e apoio}

Aos professores e alunos da Escola Municipal Raul de Queiroz de Menezes Veiga que se voluntariaram e se dispuseram a participar desta pesquisa; ao Parque Municipal Nascentes do Mindu que nos recebeu e nos orientou durante a visita com os alunos.

\section{Referências}

BRASIL (2000), Lei. 9.985, de 18 de julho de 2000. Regulamenta o art, v. 225, n. 1, 2000. (2001) Panorama da educação ambiental no ensino fundamental / Secretaria de Educação Fundamental - Brasília: MEC; SEF, 2001. 149 p.: il.

. (1998) Secretaria de Educação Fundamental. Parâmetros curriculares nacionais: Ciências Naturais / Secretaria de Educação Fundamental. Brasília: MEC / SEF, 1998. $138 \mathrm{p}$.

. (2016) Secretaria Municipal do Meio Ambiente e Sustentabilidade - SEMMAS.

Áreas Protegidas. Prefeitura de Manaus. Disponível em: http://semmas.manaus.am.gov.br/areas-protegidas/. Acesso em: 07/04/2016.

CASSIANO, K. R. M.; COSTA, R. C. (2012). Análise geográfica de áreas de risco em bacias hidrográficas urbanizadas: a bacia do Mindu em Manaus (AM). Territorium: Revista Portuguesa de riscos, prevenção e segurança, n. 19, 2012.

DE FREITAS, N. A. et al. Prática pedagógica com celular e Stop-motion em interdisciplinaridade com Artes. In: Anais do Workshop de Informática na Escola. 2016. p. 953.

DE MELO, S. K. S.; DA SILVA, J. R. R. T.; LEÃO, M. B. C. (1986). Elaboração de um Vídeo Didático Baseado na História da Química para o Ensino da Lei de Boyle. Enseñanza de las Ciencias, v. 4, n. 2, p. 111-121, 1986.

DRAY, W. T.; SIMONETTI, S. R. (2012). As Trilhas Interpretativas do Parque do Mindu em Manaus - AM: utilização e conservação. Caxias do Sul. In: Anais Seminário de 
VI Congresso Brasileiro de Informática na Educação (CBIE 2017)

Anais do XXIII Workshop de Informática na Escola (WIE 2017)

Pesquisa em Turismo do Mercosul. 16 a 17 de novembro de 2012. Mestrado em Turismo da Universidade de Caxias do Sul - RS, 2012.

FARACHE, A. (2011). A fascinante ilusão de movimento. .Net, Pernambuco, out. 2011. Revista Continente. Disponível em: < http : // WWW.revistacontinente.com.br/ sumario/189/claquete/922-a contenente / revista / claquete/13112-a-fascinante-ilusaode-movimento.html>. Acesso em: 30/11/2016.

LIMA, G. H. et al. (2015). Animações STOP MOTION no estudo contextualizado do Sistema Digestivo para o ENEM. Anais do X Encontro Nacional de Pesquisa em Educação em Ciências (ENPEC), Águas de Lindóia - SP, 2015. Disponível em: http://www.xenpec.com.br/anais2015/lista_area_05.htm. Acesso em: 19/11/2016.

LIMA, L. G.; DA COSTA CAMILlO, Wladimir (2015). Desenho Animado e Interdisciplinaridade: Técnica de Stop Motion para Fixação de Conteúdos de Química. Seminário Mídias \& Educação, n. 1, 2015.

OLIVEIRA, M. V.; RODRIGUES, L. C.; QUEIROGA, A.. Material didático lúdico: uso da ferramenta Scratch para auxílio no aprendizado de lógica da programação. In: Anais do Workshop de Informática na Escola. 2016. p. 359.

OLIVEIRA, N. R., et al. (2014). Stop Motion: uma ferramenta lúdica no processo de avaliação do ensino das ligações químicas. In: Congresso Internacional PDVL. 2014. p. 1-6.

PINHEIRO, R. F. (2009). Atividade física e ambiente urbano: lazer e desporto no entorno do Igarapé do Mindu-Manaus/AM. Dissertação para obtenção do título de mestre em Ciência do Ambiente da Universidade Federal do Amazonas - UFAM. Manaus - AM, 2009.

VALENTI, M. W. et al. Educação ambiental em unidades de conservação: políticas públicas e a prática educativa. Educação em Revista, v. 28, n. 1, p. 267-288, 2012. 